\title{
DISEÑO Y REPRESENTACIÓN Debates históricos y desafíos del presente
}

\section{Design and Representation}

\author{
Historical Debates and Challenges of the Present
}

Luciano Passarella | luciano.passarella@presi.unlp.edu.ar

Panorama Histórico y Social del Diseño

Facultad de Bellas Artes

Universidad Nacional de La Plata

Argentina

Recibido: 7/2/2018

Aceptado: 13/5/2018

\section{RESUMEN}

La representación se encuentra en la fase de prefiguración del proyecto de diseño, pero no solo como mímesis de algo que está en otra parte, sino de algo que todavía no es. Esto, además de un problema formal, es fundamentalmente ideológico y el diseño, a la vez que genera representaciones, se vale de las mismas para sus proyectos. En este sentido, resulta clave revisar algunos de los debates históricos que, durante la conformación de la disciplina, han involucrado a la problemática y cómo se replantean en la actualidad. Finalmente, se propone reflexionar sobre la función de la formación histórica en el abordaje de los actuales desafíos de la práctica profesional.

\section{PALABRAS CLAVE}

Diseño; representación; forma; historia; cultura

\begin{abstract}
The representation is in the prefiguration phase of the design project not only as mimesis of something that is elsewhere, but of something that does not exist yet. We can say that in addition to a formal problem it is fundamentally ideological and that, in a second aspect, the design, while generating representations, uses them for their projects. In this sense it is essential to review some of the historical debates that during the conformation of the discipline have involved the problematic, and how they are rethought at present. Finally, it is proposed to reflect on the role of historical training in dealing with the current challenges of professional practice.
\end{abstract}

\section{KEYWORDS}

Design; representation; form; history; culture 
El problema de la representación es clave en el marco de una cultura como la nuestra que le da un lugar tan preponderante a la imagen. Esto se evidencia en que en la actualidad resulta prácticamente inabordable todo lo que se ha escrito sobre el tema a partir del advenimiento de la modernidad. Desde la publicación del Tratado de pintura [1498] (2004), de Leonardo Da Vinci, hasta los amplios estudios contemporáneos, como El pensamiento visual (1985), de Rudolf Arnheim, o La imagen y el ojo (1987), de Ernst Gombrich, los enfoques psicológicos, sensoriales, estéticos, semióticos y de otro tipo dan cuenta del abanico de posibilidades de las representaciones (utilizadas por distintas disciplinas y actividades humanas) que, por su constante centralidad, parecen requerir de su revisión desde alguna nueva perspectiva.

Si definimos a la representación como una «figura, imagen o idea que sustituye a la realidad» (Gran Espasa Ilustrado, 1998, p. 1176), es decir, como una cosa que reemplaza a algo que "está en otra parte», podemos decir que el diseño como actividad ${ }^{1}$ implica la representación no solo de «algo que está en otra parte» sino de «algo que todavía no es». En el diseño se planifica y se prefigura. Es esa su función primordial, así se trate de piezas de comunicación visual o de objetos de uso cotidiano. Parte de la planificación se realiza mediante una prefiguración que es en sí misma una representación de lo que el objeto o la pieza será una vez que pase a la etapa de producción. En la prefiguración del proyecto reside el primer aspecto de la representación en el diseño. ${ }^{2}$

En un segundo momento, los diseñadores producen representaciones mediante la forma y operan con representaciones previas ya codificadas por el uso cultural. Es decir que trabajan con formas ya existentes: ilustraciones, fotografías, signos, símbolos -tanto en la bidimensión como en la tridimensión-, de manera explícita o implícita. Aún en las propuestas más novedosas, se encuentran incluidas representaciones previas que operan como presencia o como ausencia en las producciones materiales. La función que cumplen las representaciones en el diseño abarca tanto el qué se representa como el cómo se representa, y estos dos aspectos conforman una unidad que involucra un problema de apariencia formal, pero con un profundo trasfondo ideológico.

Los cambios operados en el contexto actual y los nuevos posicionamientos del trabajo del diseñador, requieren de revisar algunos debates históricos y situaciones del presente para repensar aspectos de la formación requerida para una mirada crítica de las representaciones en el ejercicio profesional, donde el conocimiento de la cultura y la historia adquieren un papel cada vez más fundamental.
1 En este artículo nos referimos al diseño como la actividad profesional que permite concebir, prefigurar y planificar la producción de objetos utilitarios y de piezas o sistemas de comunicación visual, que corresponden con las incumbencias de formaciones profesionales del Diseño Industrial y del Diseño en Comunicación Visual, respectivamente. Utilizamos la denominación de las carreras de la Facultad de Bellas Artes (FBA) de la Universidad Nacional de La Plata (UNLP), pero existen otras denominaciones para carreras similares que se dictan en otras casas de estudio.

2 En el ámbito del diseño el término «representación» se refiere a todos los aspectos que intervienen en la configuración de la forma en el espacio, como color, materiales, texturas, volumen. 


\section{DEBATES HISTÓRICOS}

Si nos centramos en los debates históricos disciplinares que dieron forma a la actividad para que sea como hoy la entendemos, es interesante destacar que gran parte de ellos hacen foco en el problema de la representación y de la forma.

En el siglo XIX el clasicismo llegó a un agotamiento autorreferencial en el marco de un mundo que había cambiado por el impacto tecnológico de la Revolución Industrial. La crisis de los estilos que condujo al eclecticismo historicista -estructurado en los órdenes clásicos, el ornamento y la utilización alegórica y decorativa de las imágenes- fue la respuesta. De este modo, se miró hacia el pasado ante la falta de propuestas que podía interpretar un mundo que se estaba transformando radicalmente.

Así, el movimiento inglés Arts and Crafts, de mediados del siglo XIX, planteó como reacción utópica el rescate de los oficios medievales y la preocupación por la belleza, el ornamento y la decoración para una recuperación del gusto que se estaba perdiendo por la producción industrial. Su propuesta se centró en elevar la calidad de las representaciones visuales y su reproducción tanto en los impresos como en los objetos del ámbito doméstico. Como heredero de este planteo, pero en una etapa más avanzada de la sociedad industrial, entre el siglo XIX y el XX, el Modernismo —con sus múltiples variantes del Art Nouveau, el Jugendstil y la Sezessión, entre otras- propuso reemplazar las representaciones clásicas dominantes con una novedosa propuesta formal, donde lo vegetal y lo femenino fueran los referentes predilectos para ornamentos y para imágenes decorativas.

Antes de la Primera Guerra Mundial, y como reacción al cosmopolitismo modernista, en el seno del Werkbund alemán -institución creada para promover la industria y la exportación en un contexto de puja imperialista-, se debatía sobre la necesidad de diseñar productos típicamente alemanes para abordar una problemática que implicaba transmitir identidad nacional por medio de las formas. Mientras tanto, con el impulso de las vanguardias y de las posturas radicales - como las de Adolf Loos, en 1908, con Ornamento y delito y otros escritos (1979)—, aparecía el rechazo al ornamento y a la figuración naturalista en las representaciones.

Esa ruptura, que podemos considerar como la que fundó el denominado «diseño moderno», coincidió con el cuestionamiento a la figuración naturalista, a la perspectiva y al cubo escénico en las artes visuales burguesas por parte de todo el Movimiento Moderno, que se lanzó a la búsqueda de la autenticidad, en confrontación con lo que consideraba la falsedad de la imitación del arte clásico y de 
cualquier propuesta historicista. Vale recordar que, en el denominado Manifiesto Realista (1920), Naum Gabo y Antoine Pevsner expresan las ideas vanguardistas del Constructivismo ruso: «Dejemos el pasado a nuestras espaldas como una carroña. Dejemos el futuro a los profetas. Nosotros nos quedaremos con el hoy" (Gabo \& Pevsner, 1920, s/p). De este enfoque se desprendieron los talleres Vkhutemas, considerados las primeras escuelas de diseño - junto con Bauhaus-, que luego tendrán una influencia a nivel mundial.

Ante un mundo en transformación que requería de nuevas respuestas, en las novedosas propuestas pedagógicas de estas escuelas -basadas en un formato práctico de trabajo de taller y con un esquema de maestro-aprendiz-, el estudio de la historia en general fue considerado un impedimento y puesto en último plano. ${ }^{3}$ La creación del mundo nuevo soñado por la vanguardia revolucionaria debía ser representado mediante formas nuevas. La representación de motivos clásicos fue suplantada por la síntesis, las formas geométricas y la figuración geometrizada que se asociaron con lo moderno.

Sobre la base de la idea de que «la trilogía geométrica sobre la que reposa toda creación humana tiene un valor eterno y universal» (Gropius en VV.AA., 1971, p. 13), se sostenía que las formas que surgían del cuadrado, el círculo y el triángulo contenían un significado transformador. Estudios más recientes fueron complejizando el problema (Álvarez Caselli, 2014) y debilitando esa idea, por lo que podemos decir que las formas sintéticas se percibían como radicales porque eran drásticamente distintas a las utilizadas en el pasado.

El diseño moderno pasó de estar acotado a sectores intelectuales de vanguardia a masificarse a partir de la posguerra. Los conceptos de la buena forma (expresado en el Good Design estadounidense), del Bel Design italiano o de la Gute Form alemana (difundida pedagógicamente por la escuela HFG de Ulm, con una postura crítica de Bauhaus) fueron las influencias más fuertes en la creación de las carreras en la Argentina de la década del sesenta. Se asentó la idea de que la forma debe seguir a la función y esta debía resolverse con un alto grado de síntesis y de austeridad en los recursos visuales, sin agregados decorativos. Y si bien se incorporaron disciplinas y métodos para fortalecer los fundamentos proyectuales, incluido el estudio de las ciencias sociales, la ruptura con el pasado había quedado instalada como un mandato.

Las reacciones posmodernas de la segunda mitad del siglo XX - con movimientos denominados de antidiseño, como el Grupo Memphis y Archigram, entre otros - reflejaron dicha crisis a través de la vuelta de recursos que dieron rienda suelta a la inclusión de toda una gama de representaciones figurativas en objetos funcionales - sillas con forma de lengua o percheros con apariencia de cactus, solo para nombrar
3 Se rechazó lo que se denominaba historia de los estilos, no así lo referido a la historia de la técnica y de los materiales. 
(4 En las carreras de Diseño en Comunicación Visual y Diseño Industrial de la Facultad de Bellas Artes de la Universidad Nacional de La Plata, creadas en 1962, las materias históricas disciplinares -Panorama Histórico y Social del Diseño (común para ambas carreras) e Historia del Diseño (diferenciada para cada carrera)recién se incorporaron en la reforma del plan de estudios de 1985. algunos- que sirvieron para desafiar los postulados del movimiento moderno y su hegemonía a partir de la posguerra. El rechazo al pasado heredado del diseño moderno, combinado luego con las posturas posmodernas que abordaron la historia como hechos fragmentarios, hicieron que la consolidación de una formación histórica disciplinar de los diseñadores quedara postergada por largo tiempo. ${ }^{4}$

\section{DESAFÍOS DEL PRESENTE}

En la actualidad, el ejercicio del diseño se encuentra atravesado por un contexto con características propias que genera nuevos desafíos profesionales. Рara cada problema se requiere de una solución de diseño a medida, sin axiomas absolutos que permitan aplicar un método rígido. Los recursos formales se entienden al servicio de los condicionantes del proyecto y de la respuesta esperada, y el diseñador "deberá, simplemente, escoger el referente estético o incluso crear el lenguaje formal pertinente al caso que tenga entre manos, con la mayor profesionalidad posible, y resolver así el problema de su cliente satisfaciendo al máximo los objetivos de este» (Chaves, 2001, p. 64). Para eso, resulta clave el conocimiento de un diseñador que tome decisiones para realizar el proyecto hasta en el más mínimo detalle, aunque la materialización la desarrolle un tercero. Lo que el diseñador debe tener claro en el proyecto es qué imagen necesita incluir o qué pieza requiere (con sus formas y sus materiales).

En la etapa de proyecto, por una parte, la disponibilidad de información visual (con medios electrónicos) facilita la tarea de búsqueda de representaciones, pero a la vez complejiza la labor creativa. En este sentido, se requiere de un alto conocimiento de las imágenes y de los objetos para utilizarlos adecuadamente como una suerte de archivo conceptual y visual, a fin de evitar parecidos indeseados o plagios involuntarios. El abordaje de la tarea de diseño sin una somera búsqueda previa sobre lo que ya existe es altamente riesgosa. Por otra parte, la información más accesible a través de las redes sociales puede ser engañosa o contener datos erróneos.

Actualmente, el acceso a la tecnología y a gran cantidad de información es una solución que encierra nuevos problemas. Las herramientas y los recursos han crecido exponencialmente. El problema en el presente es cómo filtrar y administrar los recursos disponibles y la respuesta radica en la formación para hacer uso de las herramientas y de la información. Se trata de desarrollar la capacidad de discernir para elegir la solución adecuada y más efectiva.

La representación es reproducción, pero también producción, es decir, posee un componente capaz de aportar en un sentido 
transformador (García Canclini, 1979). Depende de las decisiones que tome el diseñador y éstas están sujetas a una cultura. Y la cultura es básicamente la historia de las cosas, el camino que han recorrido.

El problema de la representación en el diseño está presente en los mismos debates históricos de la disciplina y es precisamente en la formación histórica donde se hallan las herramientas para dar sustento a la formación de los diseñadores, para el desarrollo de la actividad en un contexto cultural donde aumenta la circulación de representaciones.

Por esta razón, el diseño se vale de representaciones codificadas y genera nuevas representaciones en un contexto de gran saturación de información, por lo que resulta clave que el diseñador no reproduzca representaciones acríticamente, sino que desarrolle criterios sobre los códigos culturales, ya sea para seguirlos o para romperlos, y que realice propuestas que aporten a la sociedad positivamente. Para tomar decisiones le permitan dar respuestas en el marco de la cultura en la que se desenvuelve, el diseñador necesita recurrir a una formación histórica que actualmente resulta indispensable.

\section{HACIA UNA ARTICULACIÓN DE SABERES}

Como analizamos en el recorrido de los debates históricos, una influencia profunda del Movimiento Moderno fue la idea de la creación no contaminada por el pasado, que se constituyó con el tiempo en dominante de la actividad del diseño, lo que llevó a desatender la centralidad que, en articulación con la enseñanza proyectual, tiene la formación histórica para un ejercicio profesional sólido en una sociedad compleja y saturada de información. En este sentido, debe considerarse un estudio de la historia, entendida no como un saber enciclopédico, sino como un trabajo en el que se tengan en cuenta las dimensiones múltiples que componen al diseño industrial y de comunicación visual abordadas en contexto (tanto respecto a los vaivenes del desarrollo de la disciplina como de sus producciones y sus referentes). Se propone, entonces, una mirada histórica atenta de lo realizado hasta el momento, a fin de dar sentido a su articulación con la actividad proyectual, aunque el problema de diseño que se aborde sea de gran actualidad y hasta de moda. La investigación en clave histórica resulta un aporte, ya sea que los trayectos temporales sean extensos y lejanos, o breves y recientes.

Como para el estudio de la historia también utilizamos representaciones, es necesario considerar un abordaje crítico, ya que involucra enfoques ideológicos. Tanto en materiales bibliográficos como didácticos se advierte la utilización repetitiva y esquemática 
de representaciones de producciones del diseño que se han vuelto emblemáticas, muchas veces sin el análisis de su contexto ni de su situación de uso.

La historia debe funcionar como una herramienta para desnaturalizar estos enfoques y como un insumo para el trabajo del diseñador con relación a las decisiones sobre operaciones de representación que debe abordar en su ejercicio profesional. Por lo tanto, los criterios con los que se enseña la historia del diseño requieren de una revisión periódica (Bernatene, 2015). Por ejemplo, tener presente los debates históricos de la disciplina permite pensar debates o tensiones actuales en clave histórica o en referencia a problemáticas que atraviesan a las representaciones y que, no por cercanas en el tiempo, dejan de ser similares o con reminiscencias del pasado.

Para poner unos breves ejemplos, el conocimiento de las imágenes que ha producido la cultura tanto en occidente como en oriente resulta de gran utilidad para el Diseño en Comunicación Visual en lo que refiere al diseño o al rediseño de marcas con símbolos. La falta de conocimiento iconográfico puede conducir, por ejemplo, a deteriorar el escudo de una ciudad quitándole elementos clave de significado o a diseñar un signo nuevo basado en la armonía sintáctica de una forma que aluda a una esvástica. Por ello, tal como les sucede a los diseñadores industriales, conocer la historia de los objetos es clave para decidir si la forma de un producto tiene que parecerse a la tipología dominante o romper con los códigos previos.

Esta propuesta de fortalecer una formación histórica para una mejor comprensión de la cultura se opone a la hegemonía de un discurso naturalizado que las plantea como una formación meramente complementaria o accesoria. Las materias históricas están desde el comienzo de las carreras en tensión con un enfoque de la disciplina que plantea -en general de manera tácita y como distorsión posmoderna de residuales planteos vanguardistas- que el diseño está ligado a una formación esencialmente práctica en el marco de una actualidad ahistórica y a la creación ex novo, que deriva en un discurso sobre la disciplina que abusa acríticamente de conceptos, como innovación, creatividad y tecnología.

Si el significado de las formas está fundamentalmente en su historia acumulada más que en las formas en sí mismas, el conocimiento histórico resulta central porque la cultura es básicamente el pasado. No solo por la acumulación de saberes por parte de quienes nos precedieron, sino porque el desconocimiento histórico de la disciplina, así como del mundo de las imágenes y de los objetos cotidianos, encierra riesgos para la pertinencia y la efectividad de las soluciones que debe aportar el diseño. El actual desafío para el diseño no reside 
en el perfeccionamiento del uso de las herramientas disponibles para aumentar las capacidades de representación -que hoy resultan más accesibles-, sino en fortalecer el discernimiento para las decisiones a tomar en un universo de representaciones cada vez más vasto y complejo. En este sentido, una herramienta clave que posee el diseñador es una sólida formación histórica y el desarrollo de una mirada crítica que le permita conectarla con la realidad cultural del presente.

\section{REFERENCIAS}

Álvarez Caselli,P.(2014). Decirmuchocon poco:Laeconomía delaimagen como forma de representación. Diseña, (4), 136-141. Recuperado de http://diseno.uc.cl/wp/wp-content/uploads/2015/05/2012_Alvarez_ RD4_Decir.pdf

Arnheim, R. (1985). El pensamiento visual. Buenos Aires, Argentina: Eudeba.

Bernatene, R. (Comp.). (2015). Historia del diseño industrial reconsiderada. La Plata, Argentina: Edulp.

Chaves, N. (2001). El oficio de diseñar. Propuestas a la conciencia crítica de los que comienzan. Barcelona, España: Gustavo Gili.

Da Vinci, L. [1498] (2004). Tratado de pintura. Madrid, España: Akal.

Gabo, N. y Pevsner, A. (1920). Manifiesto Realista o Constructivista. Recuperado de https://es.scribd.com/doc/51120224/ManifiestoRealista-1920

García Canclini, N. (1979). La producción simbólica. Teoría y método en sociología del arte. Ciudad de México, México: Siglo Veintiuno.

Gombrich, E. (1987). La imagen y el ojo. Madrid, España: Alianza Forma. Loos, A. (1972). Ornamento y delito y otros escritos. Barcelona, España: Gustavo Gili.

VV.AA. (1971). Bauhaus. Madrid, España: Comunicación.

VV. AA. (1998). Gran Espasa Ilustrado. Madrid, España: Espasa Calpe. 